\title{
Surveillance and Management of Estrous Cycle in Awassi and Lacaune Ewes During Out of Season
}

\author{
Liviu BOGDAN ${ }^{1}$, Sanda ANDREI ${ }^{1}$, Anamaria Luciana BLAGA PETREAN ${ }^{1 *}$, Ileana BOGDAN ${ }^{2}$, Ioan PAȘCA ${ }^{1}$ \\ and Sidonia BOGDAN ${ }^{1}$ \\ ${ }^{1}$ Faculty of Veterinary Medicine, University of Agricultural Sciences and Veterinary Medicine, Mănăştur \\ Street, no.3/5, Cluj-Napoca, Romania \\ ${ }^{2}$ Faculty of Agriculture, University of Agricultural Sciences and Veterinary Medicine, Mănăştur Street, \\ no.3/5, Cluj-Napoca, Romania \\ *corresponding author: anamariapetrean@yahoo.com
}

Bulletin UASVM Veterinary Medicine 73(2) / 2016,

Print ISSN 1843-5270; Electronic ISSN 1843-5378

DOI:10.15835/buasvmcn-vm: 12370

\begin{abstract}
The purpose of this study was to increase fertility in sheep by applying modern biotechnology: induction and synchronization of estrous in non- breeding season. The ewes were divided into 3 equal batches. In all batches intravaginal sponge (Veramix/Intervet) containing $60 \mathrm{mg}$ of MPA was left in the vagina for 14 days. Immediately after removal of the sponge an injections of prostaglandin (Dinolytic/Pfizer) at the dose of $12.5 \mathrm{mg}(2,5 \mathrm{ml}) / \mathrm{animal}$ was administered in batch II. Batch III received two injections: PMSG hormone (Folligon/Intervet) at the dose of $500 \mathrm{IU} /$ animal and prostaglandin (Dinolytic/Pfizer) at the dose of $12.5 \mathrm{mg}(2,5 \mathrm{ml}) /$ animal. The research focused on several directions: assessment of estrous manifestation; occurrence of estrous interval after completion of hormonal therapy; duration of estrous; appreciation of gestation after the first and second estrous clinically manifested; percentage of fecundity. From the results obtained it follows that induction and synchronization of estrous in non-breeding season showed economic advantages by shortening the time needed for the installation of gestation, the possibility of lambing distribution, preparation and organization of mating.
\end{abstract}

Keywords: estrous, ewes, pregnancy, synchronization

\section{INTRODUCTION}

Estrous synchronization has a number of advantages in terms of intensive animal breeding because the entire technology can perform rhythmic and planned (Homeida et al., 2009). Intravaginal sponges containing progesterone are one of the most applied treatments for estrous induction and synchronization in small ruminants during the breeding and non-breeding season. Intravaginal sponges are frequently inserted for 12 to 14 day and used together with PMSG and prostaglandin, particularly out of season (Jainudeen et al., 2000; Ataman et al., 2006). Still, there are many factors influencing the effect of
PMSG, including the dose, administration time of PMSG and season (Zonturlu et al., 2011).

This aim of this study was to increase fertility in sheep by applying modern biotechnology: induction and synchronization of estrous in out of breeding season by hormonal therapy.

\section{MATERIALS AND METHODS}

The research has been carried out during April 2013 - February 2014 on 63 Awassi and Lacaune ewes, aged between 11 months and 6 years, in Lakonia region, Greece.

The ewes were divided into 3 equal batches (21 ewes). In all batches intravaginal sponges 
(Veramix/Intervet) containing $60 \mathrm{mg}$ of MPA was left in the vagina for 14 days.

In batch I hormonal treatment to induce estrous synchronization in out of season (May) was performed using intravaginal sponges impregnated with medroxyprogesterone acetate (MPA) - Veramix sponges. In batch II immediately after removal of the sponge an injection of prostaglandin (Dinolytic/Pfizer) at the dose of $12.5 \mathrm{mg}(2.5 \mathrm{ml}) /$ animal was administered. Each $\mathrm{ml}$ contains dinoprost tromethamine equivalent to $5 \mathrm{mg}$ Dinoprost and benzyl alcohol - $9.45 \mathrm{mg}$ - preservative. Batch III received two injections: PMSG hormone (Folligon/Intervet) at the dose of $500 \mathrm{IU} /$ animal and prostaglandin (Dinolytic/ Pfizer) at the dose of $12.5 \mathrm{mg}(2.5 \mathrm{ml}) /$ animal.

\section{Administration of Veramix Sponges}

Veramix sponges are polyurethane sponges impregnated with the progestogen, medroxyprogesterone acetate (MAP). The sponges are for intravaginal use only and are designed to be used a veramix applicator. Each sponge contains $60 \mathrm{mg}$ Medroxyprogesterone Acetate.

\section{DAY “0”}

Each ewe was restrained in the standing position by one operator and a second operator coats a sponge and loads it into the applicator. The vulva of each ewe should be cleaned. The applicator is gently inserted into the vagina in a slightly upwards direction at first (Step 1) and gently but firmly pushed forwards until it meets resistance (Step 2). The tube of the applicator is then slipped back out of the vagina while the rod prevents the sponge from being drawn out (Step 3). The rod is then removed, leaving the two strings protruding from the vulva (Step 4).

To observe the onset of heat, the interval that occurred, their duration, and for better management of animals subsequent maneuvers they have been individually marked.

\section{DAY "14"}

The sponges are removed 14 days after insertion In some individuals it was observed white to yellowish secretion, odorless that appeared as a result of irritation of the vaginal mucosa in contact with the rough surface of the sponge.

\section{Management of rams for controlled}

\section{breeding}

Rams management for mating was started with 1 month before the period of induction and estrous synchronization. They were separated by sheep and maintained in the best pastures. They were on supplementary feed during that time. The daily ration of a ram was $1.1 \mathrm{~kg} /$ day. Two weeks prior to the introduction of females, the rams were subjected to an internal parasite treatment. Hooves were examined as well, knowing that rams with problems in the locomotor system performs jump with difficulty or not even achieved it.

After assessment of estrous manifestation natural mating was done. The diagnosis of pregnancy was performed 30 days after mating with the aid of AGROSCAN A8 portable ultrasound.

\section{RESULTS AND DISCUSSIONS}

Regarding the occurence of estrous interval the results showed higher values for the batches at witch hormonal protocol was based on combination the source of progesterone with prostaglandin and prostaglandin with PMSG respectively. Thus, batch I to which we have just administered vaginal sponges for 14 days yielded the highest average occurrence of estrous interval - 36.57 hours. For batch II average value was 34.76 hours, while for batch III mean value obtained was 32.38 hours (Tab. 1).

Another parameter studied during the research was the duration of estrous manifestation. The recorded average values were: batch I - 28 hours, batch II - 22.47 hours and batch III - 18.85 hours (Tab. 1). There is a shorter duration of estrous in batches which were administrated hormonal protocols based on progesterone and prostaglandin or prostaglandin and PMSG.

For all the sheep included in the experiments pregnancy was confirmed after first or second estrous cycle. The rates of return to estrous at 30 days were $14.2 \%$ for batch II and $23.81 \%$ for batch I. In batch III all animals expressed estrous after first cycle (Tab. 1).

The number of lambs obtained in the first batch was 24 and the fecundity percentage was $\mathrm{P}(\%)=1.14$ with a twinning rate of $28.57 \%$ (6 sheep). In case of batch II prolificacy percentage recorded after parturition was $\mathrm{P}(\%)=1.38$. The twinning rate was $38.1 \%$ (8 sheep), while at 13 sheep was observed a simple parturition. Regarding the results recorded in batch III it was found that the percentage of prolificacy was $\mathrm{P}(\%)$ $=1.85$, yielding a total of 39 lambs. Another data obtained in this batch was that $47.62 \%$ of births 
Tab. 1. Reproductive performance of ewes treated with different hormonal therapy

\begin{tabular}{|c|c|c|c|c|}
\hline \multicolumn{2}{|c|}{ Parameters } & Batch I & Batch II & Batch III \\
\hline \multicolumn{2}{|c|}{ Occurence of estrous interval (h) } & 36.57 & 34.76 & 32.38 \\
\hline \multicolumn{2}{|c|}{ Estrous duration $(\mathrm{h})$} & 28 & 22.47 & 18.85 \\
\hline \multirow{2}{*}{$\begin{array}{c}\text { Pregnancy } \\
\text { rate }(\%)\end{array}$} & First cycle & 76.20 & 85.71 & 100 \\
\hline & Second cycle & 100 & 100 & - \\
\hline \multicolumn{2}{|c|}{ Heat returns $(\%)$} & 23.81 & 14.28 & - \\
\hline \multirow{4}{*}{ Lambs number } & Simple parturition & 18 & 13 & 10 \\
\hline & Double parturition & 6 & 16 & 12 \\
\hline & Triple parturition & - & - & 12 \\
\hline & Quadruple parturition & - & - & 4 \\
\hline \multicolumn{2}{|c|}{ Prolificacy rate $(\%)$} & 1.14 & 1.38 & 1.85 \\
\hline
\end{tabular}

was simple, double $28.57 \%, 19.04 \%$ triple and 4.76\% quadruple (Tab. 1 ).

In the present study, during the out of season period, Awassi and Lacaune ewes were administered different hormonal protocols. The occurrence of estrous was observed in the percentage of $100 \%$ for all three hormonal treatments used. The results are similar to those obtained by Zonturlu et al. (2011) (92\%, 92.6\%). Luther et al. (2007), reported rates of $86.7 \%$ and $75 \%$ in the breeding season, after using the following hormonal treatment: maintaining implants/vaginal sponges for 14/12 days in association with 400 IU PMSG. Ataman et al. (2006) reported rates of $100 \%$ estrous during breeding season using synchronization treatment with prostaglandin and 400 IU PMSG after short and long-term treatment with progesterone. During out of breeding season the estrous rate was $80 \%$.

In our study, the use of progesterone sponges alone or in association with different hormonal products (prostaglandin or progesterone) induced an estrous interval, ranging from 32.38 to 36.57 hours, between sponge removal and the onset of estrous. The time of onset of estrous was shorter than that reported by Zonturlu et al. (2011) (38.7 - 41.79 hours). The duration of estrous in the present study was shorter (18.85 - 28 hours) than that reported by Zonturlu și colab., 2011 (24.41 to 29.07 hours). Regarding the pregnancy rate the results obtained by the same authors were similar to those recorded in our study $100 \%$ pregnant sheep), while very similar values were recorded for the fecundity percentage, between 1.07-1.21 in the study of Zonturlu et al. (2011) compared to 1.14- 1.85 in our research.
Amer and Hazzaa (2009) in their study regarding the different progesterone protocols during out of season period observed that the estrous expression was ranging from $66.7 \%$ to $100 \%$, the occurrence of estrous interval ranged between 32.9 to 42.9 hours, and pregnancy rate ranged 50 - 91.7\%, depending on hormonal treatment applied. The experiments conducted by Krídli et al., 2009, on reproductive parameters in Awassi sheep breed led to the following results: estrous was detected in $92.9 \%$ - 94,8\%, the mean time to occurrence of estrous was between 42.645.8 hours and prolificacy ranged between 1.32 and 1.56 .

\section{CONCLUSIONS}

All sheep (100\%) included experiments showed estrous regardless of treatment protocol used. Occurrence of estrous interval presented the lowest average value for batch III (32.38 hours), followed by batch II (34.76 hours) and batch I (36.57 hours).For the batches which were given hormonal protocols based on progesterone and prostaglandin or prostaglandin and PMSG it was observed a shorter average duration of estrous (batch III - 18.85 hours, batch II - 22.47 hours) compared to batch (batch I - 28 hours) at which induction and synchronization of estrous was performed with vaginal sponges. The prolificacy rate is in favor of group III (P (\%) = 1.85), followed by group II (P (\%) = 1.38) and group I (P (\%) = 1.14).

From the results obtained it follows that induction and synchronization of estrous showed economic advantages: shortening the time needed for the installation of gestation, the possibility of 
lambing distribution, preparation and organization of mating.

\section{REFERENCES}

1. Amer HA, Hazzaa AM (2009). The effect of different progesterone protocols on the reproductive efficiency of ewes during the non-breeding season. Vet Arhiv 79, 1930.

2. Ataman MB, Aköz M, Akman O (2006). Induction of synchronized oestrus in Akkaraman cross-bred ewes during breeding and anestrus season: The use of shortterm and long-term progesterone treatments, Revue Méd Vét 157:257-260.

3. Jainudeen MR, Wahid H., Hafez ESE (2000). Ovulation induction, embryo production and transfer. In' Reproduction in farm animals. EDS: B Hafez/ESE Hafez, 7th edition, 405-430, Lippincott Williams-Wilkins, Baltimore, USA.
4. Homeida AM, AL-Mubarak AI and AL-Yousef YM (2009). Synchronization of Estrus in Naeimi Ewes Following Treatment with Progrestagens or Prostaglandin F2 $\alpha$, Scientific Journal of King Faisal University (Basic and Applied Sciences) 10(2):1430

5. Kridli RT, Abdullah AY, Husein MQ (2009). The effect of breed type and lactation status on reproductive performance in Awassi ewes South African Journal of Animal Science 39 (Supplement 1): 15-18.

6. Luther JS, Grazul-Bilska AT, Kirsch JD, Weigl RM, Kraft KC, Navanukraw C, Pant D, Reynolds LP,Redmer DA (2007). The effect of GnRH, eCG and progestin type on estrous synchronizati on following laparoscopic AI in ewes. Small Rumin Res 72:227-231.

7. Zonturlu AK, Özyurtlu N, Kaçar C (2011). Effect of Different Doses PMSG on Estrus Synchronization andFertility in Awassi Ewes Synchronized with Progesterone Duringthe Transition Period. Kafkas Univ Vet Fak Derg 17(1):125129. 